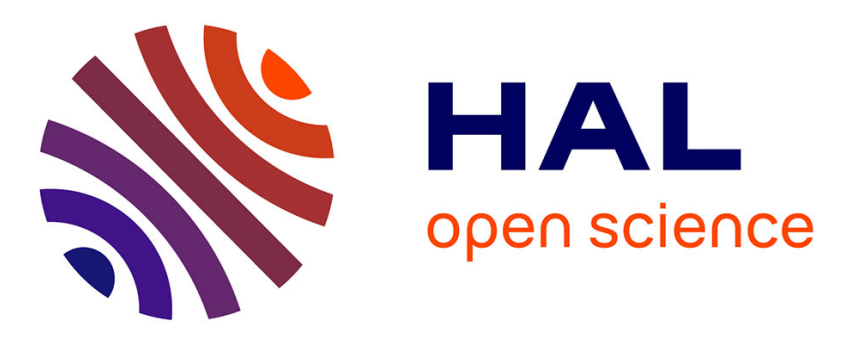

\title{
High-yield preparation of polystyrene/silica clusters of controlled morphology
}

Anthony Désert, Isabelle Chaduc, Sarah Fouilloux, Jean-Christophe Taveau,

Olivier Lambert, Muriel Lansalot, Elodie Bourgeat-Lami, Antoine Thill, Olivier Spalla, Serge Ravaine, et al.

\section{To cite this version:}

Anthony Désert, Isabelle Chaduc, Sarah Fouilloux, Jean-Christophe Taveau, Olivier Lambert, et al.. High-yield preparation of polystyrene/silica clusters of controlled morphology. Polymer Chemistry, 2012, 3 (5), pp. 1130-1132. 10.1039/C2PY20058A . hal-00685215

\section{HAL Id: hal-00685215 https://hal.science/hal-00685215}

Submitted on 12 Feb 2013

HAL is a multi-disciplinary open access archive for the deposit and dissemination of scientific research documents, whether they are published or not. The documents may come from teaching and research institutions in France or abroad, or from public or private research centers.
L'archive ouverte pluridisciplinaire HAL, est destinée au dépôt et à la diffusion de documents scientifiques de niveau recherche, publiés ou non, émanant des établissements d'enseignement et de recherche français ou étrangers, des laboratoires publics ou privés. 
COMMUNICATION

\title{
High-yield preparation of polystyrene/silica clusters of controlled morphology
}

\author{
Anthony Désert ${ }^{1,2}$, Isabelle Chaduc ${ }^{3}$, Sarah Fouilloux ${ }^{4}$, Jean-Christophe Taveau ${ }^{2}$, Olivier Lambert ${ }^{2}$, \\ Muriel Lansalot ${ }^{3}$, Elodie Bourgeat-Lami ${ }^{3}$, Antoine Thill ${ }^{4}$, Olivier Spalla ${ }^{4}$, Serge Ravaine ${ }^{5}$ and Etienne \\ ${ }_{5}$ Duguet $^{1 *}$
}

DOI: $10.1039 / c 2 p y 20058 a$

Large amounts of regular tetrapods and hexapods made of a central silica core and four or six polystyrene satellite nodules 10 were prepared with yields over $80 \%$ from $55-\mathrm{nm}$ and $85-\mathrm{nm}$ silica seeds, respectively. The robustness of the process is supported by extensive statistical analyses and large-field transmission electron microscopy images.

Colloidal clusters made of robust aggregates of a few spherical 15 particles that resemble molecules (often called "colloidal molecules”) have attracted recent interest not only as models to investigate fundamental packing questions, but also as building units for new materials expected to display unique properties established through directional interactions. ${ }^{1}$ Several synthetic 20 methods are being developed, but only a few of them are expected to combine someday production in large amounts, i.e. at the gram scale, morphology versatility and high yield in the expected morphology. ${ }^{2}$

Among the most promising ones is the aqueous seeded-growth 25 emulsion polymerization route using styrene, Synperonic ${ }^{\circledR}$ NP30, sodium persulfate and silica nanoparticles as monomer, initiator, surfactant and seeds, respectively., ${ }^{3,4}$ The surface of the silica seeds needs to be previously treated by compatibilizers, e.g. methacryloxymethyltriethoxysilane (MMS) in low surface

30 density, in order to create reactive (co)polymerizable loci promoting the surface capture of the growing macromolecules and therefore the nucleation/growth of the polystyrene (PS) nodules (Scheme 1). ${ }^{5}$ According this strategy, PS/silica clusters had been observed: snowman-like particles, ${ }^{3}$ tetrapods 35 (tetrahedrons) and hexapods (octahedrons) for a mean diameter of silica seeds of 85 and $125 \mathrm{~nm}$, respectively. ${ }^{4}$ Nevertheless, up to now the process was far to be optimal and repeatable. First, the morphology yield (calculated with respect to silica seeds) was tending to decreasing rapidly when the number of PS nodules per 40 seed was increasing, essentially because the non-monodisperse silica seeds used for these experiments were leading to mixtures of clusters whose pod number was differing from one or two units. Second, optimal morphologies had been observed for a monomer-to-polymer conversion lower than $30 \%$. Therefore, 45 tedious purification efforts were necessary for removing styrene excess from the aqueous cluster dispersion before characterization and use.

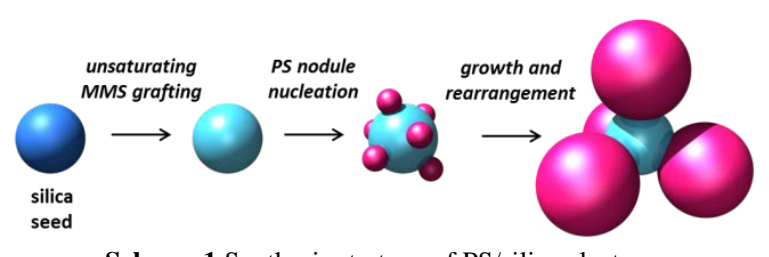

Scheme 1 Synthesis strategy of PS/silica clusters.

50 As a result, getting large amounts of identical and regular clusters was envisaged in the present work on the dual front of the narrowing of the silica size-distribution and the completion of the styrene polymerization. We focused on the synthesis of tetrapods since such structures might be used as building blocks 55 for the fabrication of diamond-like colloidal crystals with a complete photonic band gap. ${ }^{6}$ Special efforts were dedicated to extensive calculations of morphology yields and features from the statistical analysis of electron microscopy images and to the checking of the synthesis repeatability.

60 The preparation of size-monodisperse batches of silica particles was performed thanks to a first nucleation/growth stage leading to silica "pre-seeds", 7 combined with regrowth stages allowing simultaneously to reach precisely the expected diameter. The first stage used L-arginine as base catalyst, while 65 tetraethoxysilane (TEOS) as silica precursor was heterogeneously delivered in the amino-acid aqueous solution from a top organic layer. ${ }^{8}$ Different batches of silica "pre-seeds" were prepared by simply varying the volume of TEOS introduced. It was demonstrated that their final number concentration does not vary 70 significantly and that only their average diameter depends on the TEOS amount with values ranging from 17 to $34 \mathrm{~nm}$ (See ESI, Figure S1). Polydispersity index (PDI) values were systematically found lower than 1.04. Regrowth experiments were performed in order to get several batches of silica seeds of controlled size and 75 PDI targeting the values of $85 \mathrm{~nm}$ and 1.005, respectively. TEOS was added at a controlled rate and its hydrolysis/condensation was catalysed by ammonia in ethanol. One or two regrowth stages were necessary for adjusting the final diameter to the target values (See ESI, Table S1). The regrowth stages lead to a 80 significant narrowing of the size distributions allowing reaching PDI values as low as 1.002. Moreover, Transmission Electron Microscopy (TEM) images showed that regrown silica particles were more regular in shape than the initial "pre-seeds" (See ESI, 


\section{Figure S2).}

Concerning the styrene polymerization recipe, we took advantage of the complementary roles of non-ionic and ionic surfactants for controlling the arrangement of the PS pods around 5 the silica seeds and increasing the polymerization kinetics, respectively. Using a mixture of Synperonic ${ }^{\circledR}$ NP30 and sodium dodecylsulfate (SDS) (95/5 wt. \%), the rate of styrene consumption was greatly increased making the polymerization complete in 5 h (See ESI, Figure S3). This result was supported 10 by the latex particle concentration, because the polymerization rate in emulsion polymerization is known to be proportional to the particle number. Indeed, $\mathrm{N}_{\mathrm{PS}}$ was determined to be $2.2 * 10^{16}$ $\mathrm{L}^{-1}$ against $10^{16} \mathrm{~L}^{-1}$ without SDS. The size-distribution of the final latex particles was also found to be narrowed with PDI values 15 lower than 1.001 (See ESI, Figure S4). Lastly, the polymerization appeared to be reproducible with average diameters of $189 \pm 4$ $\mathrm{nm}$ on the basis of four batches prepared in identical conditions.

The preparation of PS/silica clusters was first carried out from the size-monodisperse batches of 85-nm silica particles, which 20 were previously surface-modified with MMS at the nominal surface density of 0.5 function. $\mathrm{nm}^{-2}$. Such a diameter had been previously demonstrated to be optimal for getting tetrapods. ${ }^{4}$ Nine polymerisation experiments were performed using the new recipe in identical conditions (See ESI, Table S2) and the 25 resulting clusters were statistically analysed by TEM by counting a minimum of 600 clusters per batch. Surprisingly, most of the fabricated clusters weren't tetrapods, but hexapods with an average yield of $82 \pm 5 \%$ (Figure 1). The average PS nodule diameter was $150 \pm 6 \mathrm{~nm}$ against $189 \pm 4 \mathrm{~nm}$ in the absence of 30 silica seeds, revealing that, concurrently to surfactant molecules, the MMS-modified silica seeds help in stabilizing the PS nuclei and therefore contribute to an increase of the number of PS particles which are consequently smaller at complete monomerto-polymer conversion. Most of the hexapods appeared highly 35 symmetrical thanks to the narrow size-distribution of the PS nodules, their regular arrangement on the silica seed and the fact that most of them were in contact with the TEM grid via three PS nodules making the main axis of the triangular antiprism parallel to the observation axis. The main by-products were essentially 40 clusters with a number of PS nodules lower than 6 , and some of them were obviously hexapods which were partially broken during the TEM grid preparation because the released latex particles were observed in their surrounding environment (Figure 1). Moreover, no cluster bearing more than 6 PS nodules was 45 observed, except rare ones which weren't made of a single silica core, but of a silica doublet (See ESI, Figure S5). In the pie chart, these clusters are called "multi-silica”.

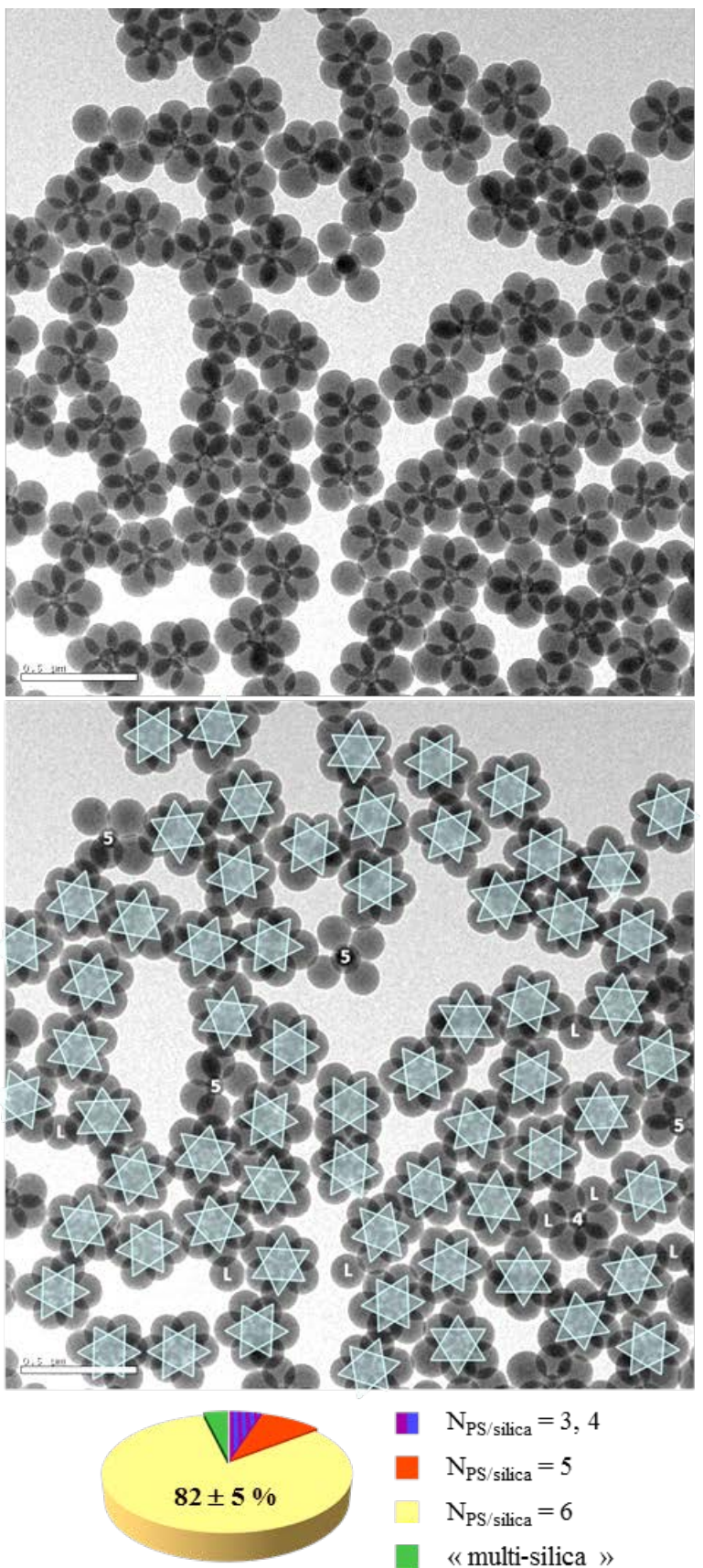

Fig. 1 TEM image of hexapods obtained by styrene emulsion polymerization from 85-nm silica seeds (batch \# H8). On the bottom image, the undoubtedly-identified hexapods were labelled for appreciating the yield of hexapod morphology: from this single image, it 55 was estimated to $93 \%$ with respect to silica seeds (64 hexapods against 5 silica seed bearing five or four pods, labelled “5” or “4”, respectively). Free (or torn) PS particles have been labelled with the letter "L" for latex (scale bar: $200 \mathrm{~nm}$ ). The pie chart displays the overall statistical results over 9 fabrication batches (See ESI, Table S2).

${ }_{60}$ The fact that hexapods were obtained instead of tetrapods may be quite easily explained by the diameter of the PS nodules which reached a final average value lower than that observed in the previous study. ${ }^{4}$ The smaller the nodules, the higher the average number of those which may be accommodated on the surface of 65 each silica seed. This factor is indeed included in the multiplicative constant $\mathrm{K}$ of the equation used for calculating the 
silica-seed diameter $\left(D_{\text {silica }}\right)$ as a function of the number of PS nodules per silica seed $\left(\mathrm{N}_{\mathrm{PS} / \text { silica }}\right){ }^{4}$

$$
\frac{D_{\text {silica }}}{2}=K\left(\frac{2 N_{P S} / \text { silica }}{3}-\frac{1}{2 N_{P S} / \text { silica }}\right)
$$

A first calculation based on the results showing that hexapods 5 were mainly obtained with $85-\mathrm{nm}$ silica seeds allowed to determine that $\mathrm{K} \sim 10.9$ (against the previous value of $16.2^{4}$ ). A second calculation indicated that tetrapods could be obtained for silica seeds with a diameter of about $55 \mathrm{~nm}$. MMS-modified seeds were prepared in this size range (See ESI, Table S1) and 10 used in emulsion polymerization of styrene at the concentration of $1.8 * 10^{16} \mathrm{~L}^{-1}$. Six batches of clusters were prepared in identical conditions and thoroughly analysed by TEM (See ESI, Table S3). The results showed that the concentration of PS nodules $\left(\mathrm{N}_{\mathrm{PS}}=\right.$ $5.1 * 10^{16} \mathrm{~L}^{-1}$ ) was increased again to the detriment of their size $15(145 \pm 4 \mathrm{~nm})$. As expected, tetrapods were mainly obtained with an average yield of $81 \pm 3 \%$. As seen on some TEM images, the yield may reach locally $100 \%$ (Figure 2), which illustrates the ability of the tetrapods to self-organize and segregate in specific areas.
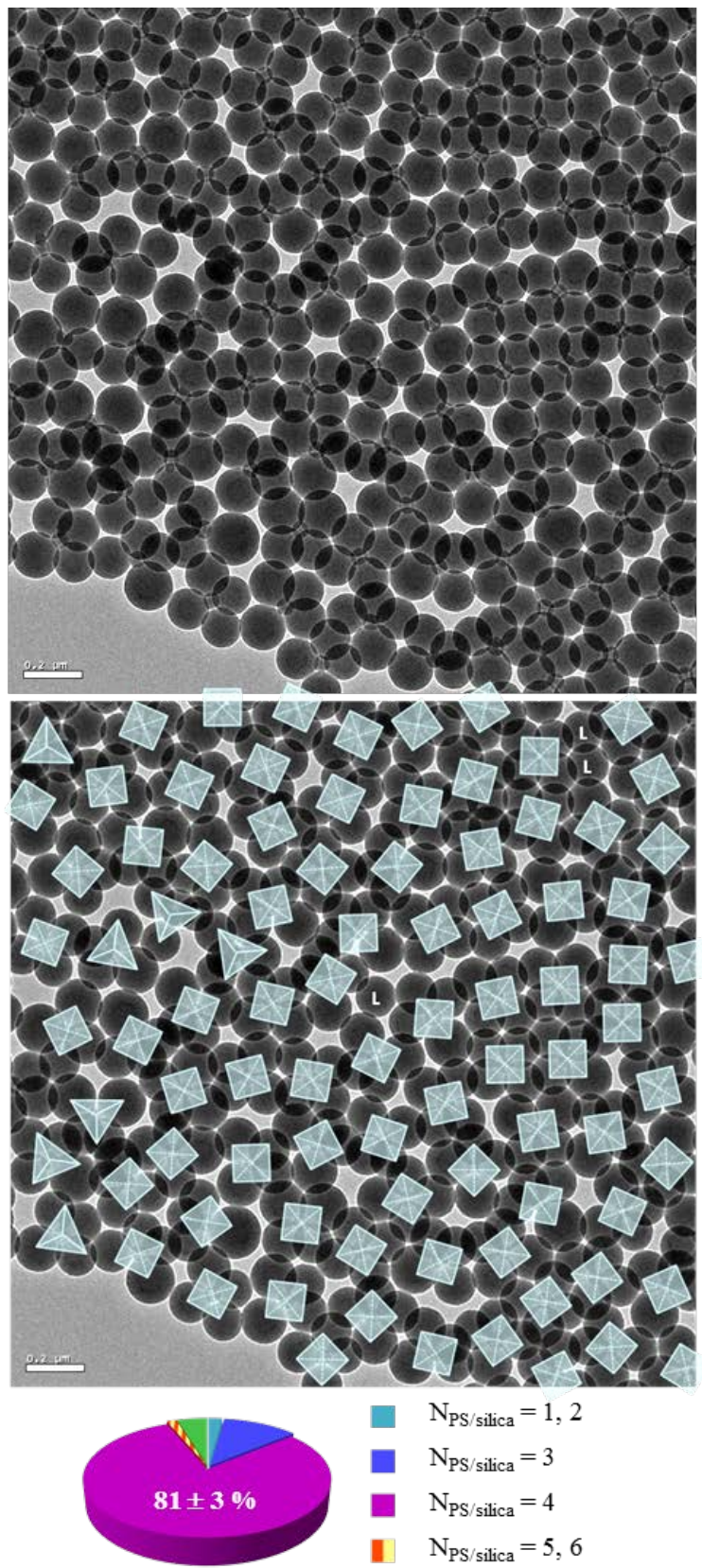

$$
\begin{aligned}
& \mathrm{N}_{\mathrm{PS} / \text { silica }}=1,2 \\
& \mathrm{~N}_{\mathrm{PS} / \text { silica }}=3 \\
& \mathrm{~N}_{\mathrm{PS} / \text { silica }}=4 \\
& \mathrm{~N}_{\mathrm{PS} / \text { silica }}=5,6 \\
& \text { «multi-silica » }
\end{aligned}
$$

Fig. 2 TEM image of tetrapods obtained by styrene emulsion polymerization from 55-nm silica seeds (batch \# T4). On the bottom image, the undoubtedly-identified tetrapods were labelled with two types

of patterns depending on their arrangement onto the substrate for appreciating the yield of tetrapod morphology: from this single image, it was estimated to $100 \%$ with respect to silica seeds (88 tetrapods against no extra cluster). Free (or torn) PS nodules have been labelled with the letter "L" for latex (scale bar: $200 \mathrm{~nm}$ ). The pie chart displays the overall

\section{Conclusions}

Highly regular PS/silica tetrapods and hexapods were obtained at complete monomer-to-polymer conversions and with typical morphology yields over $80 \%$ with respect to silica seeds. The ${ }_{35}$ determination of the nature of the by-products revealed the morphology yield could be probably increased again in 
optimizing the seed dispersion for promoting the formation of clusters made of a single silica core. Nevertheless, as far as we know, this paper is the first report where such yields were obtained for "colloidal molecules" or related complex colloids, 5 and supported by extensive statistical analyses of TEM images. Moreover, the amounts of clusters obtained per batch are at the gram scale, i.e. typically 70 g. $\mathrm{L}^{-1}$. Therefore, extensive studies of their assembling ability are henceforth possible.

\section{Notes and references}

$10{ }^{1}$ CNRS, Univ. Bordeaux, ICMCB, UPR 9048, F-33600 Pessac, France, Fax: +33 540002 761; Tel: +33 540002 651; E-mail: duguet@icmcbbordeaux.cnrs.fr

${ }^{2}$ Univ. Bordeaux, CNRS, CBMN, UMR 5248, F-33600 Pessac, France.

${ }^{3}$ Université de Lyon, Univ. Lyon 1, CPE Lyon, CNRS, UMR 5265,

15 Laboratoire de Chimie, Catalyse, Polymères et Procédés (C2P2), LCPP group, F-69616 Villeurbanne, France.

${ }^{4}$ Commissariat à l'Energie Atomique, DSM/IRAMIS/SIS2M/LIONS, UMR CEA/CNRS 3299, F-91191 Gif-sur-Yvette, France.

${ }^{5}$ CNRS, Univ. Bordeaux, CRPP, UPR 8641, F-33600 Pessac, France.

20

† Electronic Supplementary Information (ESI) available: Experimental details; Chemical structures of the main chemicals used; Evolution of the diameter and particle concentration of silica " pre-seeds " as a function of the added amount of TEOS; Experimental conditions for the silica 25 regrowth stages and size measurement results of the 85-nm and 55-nm silica seeds; TEM images of silica " pre-seeds ", silica seeds obtained after a $1^{\text {st }}$ and $2^{\text {nd }}$ regrowth stage; Influence of the substitution for 5 wt.\% of Synperonic ${ }^{\circledR}$ NP30 by SDS on the evolution of the monomer-topolymer conversion; TEM images of PS particles obtained in the absence 30 of silica seeds; Experimental conditions for the synthesis of silica/PS clusters from $\sim 85$-nm silica seeds and their main morphology features as extracted from the statistical analysis of TEM images; SEM image of hexapods obtained by styrene emulsion polymerization from $~ 85-\mathrm{nm}$ silica seeds; Experimental conditions for the synthesis of silica/PS

35 clusters from $\sim 55-\mathrm{nm}$ silica seeds and their main morphology features as extracted from the statistical analysis of TEM images. See DOI: $10.1039 / \mathrm{b} 000000 \mathrm{x} /$

‡ The authors thank Sonia Gomez for SEM experiments performed at 40 CREMEM facilities. The support of the Conseil Régional d'Aquitaine and the Agence Nationale pour la Recherche is gratefully acknowledged for ICMCB, CRPP and CBMN facilities, and ToCoMo project (contract \# ANR-07-BLAN-0271), respectively.

451 A. van Blaaderen, Nature,2006, 439, 545; F. Li, D. P. Josephson, A. Stein, Angew. Chem. Int. Ed., 2011, 50, 360; S. Sacanna, D. J. Pine, Curr. Opin. Colloid Interface Sci., 2011, 16, 96.

2 E. Duguet, A. Désert, A. Perro, S. Ravaine, Chem. Soc. Rev., 2011, 40, 941.

503 S. Reculusa, C. Poncet-Legrand, A. Perro, E. Duguet, E. BourgeatLami, C. Mingotaud, S. Ravaine, Chem. Mater., 2005, 17, 3338.

4 A. Perro, E. Duguet, O. Lambert, J. C. Taveau, E. Bourgeat-Lami, S. Ravaine, Angew. Chem. Int. Ed., 2009, 48, 361.

5 E. Bourgeat-Lami, M. Insulaire, S. Reculusa, A. Perro, S. Ravaine, E.

55 Duguet, J. Nanotech. Nanosci. 2006, 6, 432.

6 V. N. Manoharan, M. T. Elsesser, D. J. Pine, Science, 2003, 301, 483.

7 Exceptionally, the term "pre-seeds" is employed in this paper for describing the very small silica particles obtained at the end of the first stage, because the term of "seeds" is used here for describing the silica particles introduced in the styrene emulsion polymerization.

8 K. D. Hartlen, A. P. T. Athanasopoulos, V. Kitaev, Langmuir, 2008, 24, 1714; S. Fouilloux, A. Désert, O. Taché, O. Spalla, J. Daillant, A. Thill, J. Colloid Interface Sci., 2010, 346, 79; S. Fouilloux, O. Taché, O. Spalla, A. Thill, Langmuir, 2011, 27, 12304.

\section{Graphical abstract}

Large amounts of regular tetrapod-like silica/polystyrene clusters are obtained through an optimized process based on the emulsion polymerization of styrene in the presence of 55-nm silica seeds.

70

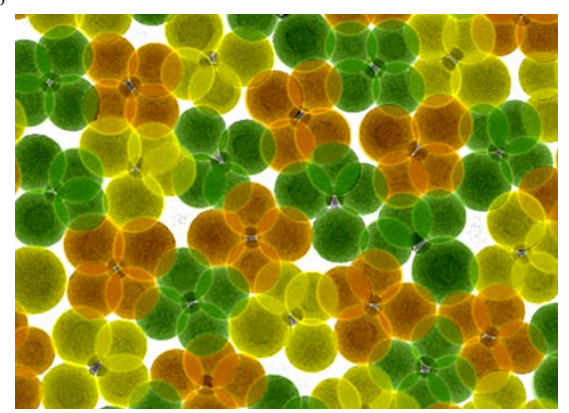

